\title{
Progressive Muscular Atrophy
}

National Cancer Institute

\section{Source}

National Cancer Institute. Progressive Muscular Atrophy. NCI Thesaurus. Code C85027.

A rare, milder form of amyotrophic lateral sclerosis. It is characterized by a slowly

progressive clinical course. Signs and symptoms include muscle weakness, atrophy, and fasciculation. 